\title{
Multimodality Neuromonitoring in Pediatric Neurocritical Care: Review of the Current Resources
}

\author{
Michael A. Galgano ${ }^{1}$, Zulma Tovar-Spinoza ${ }^{1}$ \\ 1. Neurosurgery, SUNY Upstate Medical University
}

$\square$ Corresponding author: Michael A. Galgano, mgalgano13@gmail.com

Disclosures can be found in Additional Information at the end of the article

\section{Abstract}

Brain insults in children represent a daily challenge in neurocritical care. Having a constant grasp on various parameters in the pediatric injured brain may affect the patient's outcome. Currently, new advances provide clinicians with the ability to utilize several modalities to monitor brain function. This multi-modal approach allows real-time information, leading to faster responses in management and furthermore avoiding secondary insults in the injured brain.

Categories: Pediatrics, Pediatric Surgery, Neurosurgery

Keywords: pediatric, brain injury, multimodal monitoring

\section{Introduction And Background}

In the pediatric population with brain injury, the ideal modality of intracranial monitoring is a topic of debate with very few papers dedicated to this matter. Different etiologies have been cited as a cause for alterations in cerebral pathophysiology in children, such as traumatic brain injury, ischemic events, hydrocephalus, inflammatory encephalitis, spontaneous intraventricular hemorrhage, and intraparenchymal and subarachnoid hemorrhage [1-4]. Aneurysms and arteriovenous malformations, although quite infrequent in this population, do occur and have the potential to cause devastating neurological sequelae [4-7].

Currently, we look at the insulted brain from different perspectives. In this paper, we present a review of the current modalities of monitoring the insulted pediatric brain to gather the best possible information to optimize brain recovery.

Received 09/28/2015 Review began 10/07/2015 Review ended 11/09/2015 Published 11/20/2015

C) Copyright 2015

Galgano et al. This is an open access article distributed under the terms of the Creative Commons Attribution License CC-BY 3.0., which permits unrestricted use, distribution, and reproduction in any medium, provided the original author and source are credited.
Traditionally, the result of a severe intracerebral insult to a child is increased intracranial pressure (ICP). ICP has been the parameter of choice to monitor in children with a low Glasgow Coma Scale (GCS), decreased neurological status, and abnormal neuroradiographic findings. Lumbar puncture (LP) has been historically the most basic method of assessing the intracranial pressure that yields a numerical value, measuring both opening and closing pressures [8]. However, LP is not always recommended or obtainable as a result of body habitus, clinical condition, or anatomical variations [9-10].

In the 1960's, Lundberg initiated the advent of intraventricular pressure monitoring [11], and the cannulation of the ventricle became the gold standard for measuring ICP. However, ventriculostomy has the risks of malposition, hemorrhage, and infection as potentially associated adverse events [12-13]. As a result of this, alternative ICP monitoring modalities 
have developed over the last few decades [14-15]. Subdural devices based on saline-filled transducers and electrical impedance came about in the 1980's [16] but grew out of favor because of problems associated with ICP measurement drift over time. In cases of severe traumatic brain injury with significant edema and small ventricles, ventricular catheterization becomes a challenge. Extraventricular devices, such as intraparenchymal microsensors, were developed to give clinicians an alternate way of monitoring ICP. Intraparenchymal monitors play a crucial role in providing readings very similar to those produced via ventricular catheterization. They have a lower profile and pose fewer risks to the patient [8].

More recently, an emphasis has been placed on monitoring other parameters aside from intracranial pressure. Brain oxygen tension and temperature, biochemical analysis, and invasive and non-invasive electroencephalography are now being utilized to guide further treatment in the pediatric neuro-ICU setting [15].

\section{Review}

\section{Intracranial monitoring and pediatric age}

Reported animal studies have suggested that age plays a role in the response of the brain to a traumatic event. Younger animals tend to display a longer decrease in cerebral blood flow and hypotension than older-aged animals in response to a diffuse traumatic brain injury [14, 17-18]. Inflammation also plays a significant role in pediatric brain injury; levels of interleukin- 6 and interleukin-10 become elevated in the cerebrospinal fluid (CSF) of infants and children in response to a severe traumatic brain injury (TBI) [19-20]. There is also an age-dependent production of interleukin-1, and children younger than four years old tend to display higher concentrations of this inflammatory mediator [19-20].

Within the first few months of life, some children, both premature and term infants, experience germinal matrix hemorrhages and choroid plexus hemorrhages, respectively [1, 21]. One of the most basic clinical methods of intracranial pressure monitoring in this age group, although imprecise and without a numerical value, is palpation of the open anterior fontanel and cranial sutures, as well as serial head circumference measurements [22-23]. The open anterior fontanel serves as a surrogate for indirectly assessing ICP, and a splaying of the cranial sutures beyond what is felt to be within the normal range is also of subjective clinical value [24]. Increased daily measurements of the head circumference, coupled with a full and tense fontanel, as well as splayed sutures may suggest an increased intracranial pressure. Kaiser and Whitelaw simultaneously assessed intracranial pressure in neonates by palpation of the anterior fontanel and direct measurement via cerebrospinal fluid compartment cannulation. The mean pressure was found to be significantly different between "soft" (5.4 mmHg) and "tense" (14 mmHg) fontanels. Despite these differences, there was considerable overlap [25]. Hence, the full reliability of this surrogate for intracranial pressure monitoring is cautioned.

There is a lack of consensus on the "normal value" of ICP in children. Such parameters have been well established to some degree in the adult population. However, establishing such values is more challenging in the pediatric population, given the rapidly changing intracranial physiology as a child grows. Knowledge of the accepted intracranial pressure values based on age differences is critical to the clinician during interpretation of invasive monitoring, i.e., an ICP that would otherwise be interpreted as "benign" in a teenager may be severely pathological in a three-year-old child. Between the ages of four and 16, the highest acceptable value for ICP is agreed upon to be $12.9 \mathrm{mmHg}$. An upper limit of $5 \mathrm{mmHg}$ is typically regarded as normal in a mechanically ventilated infant after a TBI. A slightly older child in a similar clinical scenario should have an ICP no higher than $10 \mathrm{mmHg}$ [8, 26-27]. Mehta and colleagues examined the relationship between intracranial pressure and cerebral perfusion pressure. They concluded that children with a traumatic brain injury subsequently having an 'unfavorable outcome' had 
more frequent recordings of a cerebral perfusion pressure $<45 \mathrm{mmHg}$ in comparison to children with a 'favorable outcome'. This study suggested a target cerebral perfusion pressure of at least $45 \mathrm{mmHg}$ to avoid brain ischemia [28].

\section{Indications for multimodal monitoring}

The mean objective in placing a device to monitor a specific parameter of interest is the early detection of abnormal processes to avoid secondary brain insults. Insults from decreased substrate delivery, hypoxia, hypoglycemia, hypotension, hypovolemia, worsening or development of cerebral edema and intracranial hypertension, hyperglycemia, hypercapnia, cellular toxicity, hyperglycemia, hyperoxemia, increased metabolism, fever, seizure, negative nitrogen balance, systemic derangement, infection, venous thrombosis, drugs, or multifactorial processes. With monitoring, neuro-intensivists can individualize therapeutic goals. Optimizing treatment dosing and timing reduces potential adverse effects of an intervention, hopefully translating to improved outcome. Also, monitoring enables the understanding of the pathophysiology regarding complex processes occurring simultaneously in the injured brain. Intracranial pressure monitoring alone may not detect other metabolic dysfunctions leading to secondary injury. Hence, there is a role for multimodal monitoring in the insulted pediatric brain [29]. It should be kept in mind that the majority of devices on the market are made to accommodate an adult-sized skull thickness. A need exists to specifically develop monitoring devices that will fit appropriately in order to obtain the most accurate readings.

\section{Lumbar Puncture (LP)}

First described in 1891 by the German physician, Heinrich Quincke, the lumbar puncture (LP) is one of the oldest methods of indirectly measuring intracranial pressure [30]. Reliance on the manometer reading for opening pressure rests on whether one believes that the pressure gradient between the intracranial cavity and lumbar cistern is essentially negligible [31-32]. After an intracerebral insult, cerebrospinal fluid does not circulate freely as it would normally; CSF volume may actually be low as a result of compensatory mechanisms instituted by the brain to accommodate a new inhabitant, whether it is blood or edema. There has always been a question of whether there is one uniform intracranial pressure, or whether ICP is compartmentalized [12, 33]. A non-communicating ventricular system with the spinal theca may yield an unreliable "ICP value" obtained via a lumbar puncture [34-35]. Lumbar punctures can be challenging in the setting of a neonate or a compartmentalized intrathecal space. It should also be kept in mind that this maneuver has the potential to result in tonsillar herniation in some patients [34-35]. As with placement of a lumbar drain, it is of vital importance prior to performing a lumbar puncture to ensure that there is no significant supratentorial mass effect and that there are radiographically open basal cisterns.

Lumbar Drain (LD)

Studies have shown efficacy in the use of lumbar drains as a means for controlling increased intracranial pressure. However, data is lacking in regards to the use of continuous ICP monitoring utilizing a lumbar drain in the neurocritical care patient population after sustaining a brain injury [31]. After a significant intracerebral insult, whether it be from significant head trauma or spontaneous subarachnoid hemorrhage, an external ventricular drain (EVD) is often utilized for both diagnostic and therapeutic purposes. Subsequent placement of a lumbar drain in cases of medically refractory intracranial hypertension, even after an EVD has been placed, has shown a significant reduction in ICP measurements [36-39]. The most feared complication in regards to placement of a lumbar drain in the setting of increased intracranial pressure is the potential for downward tonsillar herniation [40]. As with LP, this can occur as a result of overdrainage through the lumbar cistern, which can be potentiated by a high cranial to a caudal pressure gradient. This highlights the fact that controlled use of a lumbar drain for both 
therapeutic and diagnostic purposes in the pediatric brain injury population is best instituted with basal cisterns radiographically open and no evidence of a significantly-sized lesion causing mass effect and midline shifting up structures. It may also be a safer option to place an external ventricular drain prior to institution of a lumbar drain [41]

\section{External Ventricular Drain (EVD)}

Claude-Nicholas Le Cat performed the first documented external ventricular drain (EVD) in 1744 for congenital hydrocephalus. Evolution of this technique has taken place over time [42]. EVDs have become the gold standard to measure intracranial pressure [43]. In addition to being a diagnostic tool for measuring ICP, EVDs are also used for therapeutic purposes [8]. Common indications for placing an EVD in the pediatric population include traumatic brain injury, acute hydrocephalus from various causes, and ventriculoperitoneal shunt failure [44]. Complications with the placement of an external ventricular drain include misplacement (which can lead to neurological deficits), infection, hemorrhage, and malfunction necessitating replacement [44]. Rates of secondary EVD-related infection in regards to placement in the pediatric intensive care unit as opposed to the operating room (OR) have not been assessed [44]. Ngo, et al. specifically looked at rates of EVD-related complications in pediatrics; in this study, 66 patient charts were reviewed, and 96 EVD's were placed [44]. The overall total complication rate was $26 \%$. Catheter infection occurred in $9.4 \%$, catheter misplacement was seen in $6.3 \%$, and hemorrhage was seen as a complication in $4.2 \%$ of insertions. Adult literature, as well as the results obtained from Ngo, et al., agree that EVDs inserted at the bedside with sterile technique were not associated with higher complications rates when compared to EVDs inserted in the operating room [44-45]. Patients with traumatic brain injury and small ventricular size have not shown an increased risk of EVD misplacement versus pediatric patients with

hydrocephalus. Placement of adult size trauma EVDs in small pediatric ventricles may also yield false values, given the collapse of the ventricular walls around the device.

\section{Transcranial Doppler (TCD)}

Transcranial Doppler (TCD) has been a vital non-invasive tool in the repertoire of the neurocritical care team allowing real-time monitoring of physiological changes in the blood flow velocity. In the adult population, TCDs are routinely used to assess for vasospasm following spontaneous subarachnoid hemorrhage to detect velocity changes of blood flow consistent with an elevation of ICP [46]. In the pediatric brain trauma population, it has been suggested that TCD could be used as an initial monitoring modality to indirectly measure ICPs and cerebral perfusion pressure (CPP). TCD has shown to have a $94 \%$ sensitivity (possibility of screening patients for potentially elevated ICP) and a $95 \%$ negative predictive value (ability to identify patients with a normal ICP) [47]. Furthermore, TCD can be performed within the first few minutes of a patient arriving at the hospital if there is a concern for increased intracranial pressure. On the contrary, Figaji, et al. concluded that the pulsatility index of TCDs is not a consistent representation of intracranial pressure in children with significant TBIs. In their study, they only found a minor association between the pulsatility index and the ICP [48]. Further studies are necessary to help establish the relationship between transcranial Doppler pulsatility index and CPP.

TCDs have also been used to evaluate cerebral autoregulation (AR); when the mean arterial pressure (MAP) elevates, constriction of the intracranial vasculature takes place. Conversely, the intracranial vasculature dilates as the mean arterial pressure decreases. This physiological event remains constant over a MAP range from 50 to $150 \mathrm{mmHg}$ in the uninjured brain of an adult [43]. A formula was created to measure if the autoregulatory response is appropriate utilizing the transcranial doppler. The formula is $\mathrm{ARI}=\% \Delta \mathrm{eCVR} / \% \triangle \mathrm{MAP}(\mathrm{ARI}=$ autoregulation index, eCVR = estimated cerebrovascular resistance, $\mathrm{MAP}=$ mean arterial 
pressure). An autoregulatory index $\geqslant 0.4$ is regarded as normal. Autoregulatory impairment has been observed in as many as two-thirds of adults and $40 \%$ of the pediatric population with significant traumatic brain injuries [49-52]. It has also been related to an overall poor outcome in both pediatric and adult traumatic brain injury patients. However, it is not clear if autoregulatory impairment is itself an isolated variable leading to a significantly decreased clinical outcome [53-55].

\section{Parenchymal Intracranial Pressure Monitoring}

The most widely used and commercially available device for direct parenchymal ICP monitoring is named the Camino (Integra Life Sciences, New Jersey). The monitor itself is a fiber optic lead inserted directly into the brain parenchyma to a predetermined depth. It is designed for rapid placement in the neuro-ICU setting to provide an immediate ICP value and associated waveform. Intraparenchymal ICP monitoring devices are safe with a rather low complication rate [56]. Procedure-related complications, such as brain contusion, epidural hematoma, and catheter disconnection have been reported [56]. As a disadvantage, these devices are not MRIcompatible. This limits its use in children where MRI is often favored over repeated CT scans, as MRI yields prognostic information and also limits exposure to radiation from CT scans. Besides, ICP "drift” has been a well-documented limitation, whereby the values obtained may lose reliability with time [57]. In small children, with thinner skulls compared to adults, nonbolted devices are often necessary, given the inability of the skull to support the bolted version. The depth of the bolt itself has the potential to exceed the skull thickness, putting the underlying brain at risk during placement. Tunneled versions of such intraparenchymal monitors have been designed, excluding the need for a bolt, but implying a greater likelihood of malposition due to the lack of a "guiding system" for insertion.

\section{Continuous Brain Tissue Oxygen Monitoring}

Brain tissue oxygenation ( $\mathrm{PbtO} 2$ ) has been a more novel target parameter that has been studied in the adult and pediatric population in regards to TBI as well as subarachnoid hemorrhageinduced vasospasm. PbtO2 monitoring is utilized via an invasive method, whereby an electrode is inserted into a specific area of interest in the brain parenchyma. $\mathrm{PbtO} 2$ is measured by the utilization of the Licox device (Integra Life Sciences, New Jersey). Licox is a triple lumen device allowing simultaneous monitoring of ICP, $\mathrm{PbtO} 2$, and brain temperature. In the head-injured population, it has been shown that brain temperature exceeds systemic temperature and may increase on average by 2.0 degrees $\mathrm{F}$ (1.1 degrees $\mathrm{C}$ ) above the core body temperature [58]. As we aim to avoid hyperpyrexia in the brain-injured patient, establishment of target core brain temperatures in the pediatric population needs to be established.

The Licox is placed at Kocher's point unless placement in that region would entail insertion into a known hematoma or ischemic region, which may ultimately yield false values. The catheter membrane allows oxygen to diffuse across it, and this subsequently generates a voltage. The degree of oxygenation at the specific electrode site is proportional to the generated voltage. Still, the physiological representation of the brain-tissue-oxygen-tension value continues to be under investigation [59]. It has been reported that diminished oxygenation of brain tissue is associated with a worse prognosis [17, 60-62]. However, there is not enough data available to support that $\mathrm{PbtO} 2$ in children with cerebrovascular accidents would aide in the prevention of progressive ischemic events and ultimately improved outcome [17]. Narotam, et al. were able to show that a brain tissue oxygenation-directed protocol reduced the mortality rate after major traumatic brain injury in a patient population with a mean age of 35 years. It also resulted in an improved six-month clinical outcome over the standard ICP/CPP-directed therapy at the authors' institution [16]. Figaji and colleagues demonstrated that reduced PbtO2 in children after sustaining a severe traumatic brain injury appears to be an independent factor 
associated with poor outcomes [63-64]. PbtO2 values $<10 \mathrm{mmHg}$ had a significant association with an irreversible brain insult. The most recent consensus on pediatric TBI guidelines made a Level III recommendation to give consideration to maintaining a PbtO2 $\geqslant 10 \mathrm{mmH} 2 \mathrm{O}$ [65]. Stippler and colleagues studied the utilization and outcomes of PbtO2 monitoring in children with severe TBI's, with simultaneous ICP and CPP recording. Results demonstrated some instances of unfavorable clinical results with altered ICP and CPP values, despite normal PbO2 values [66].

The interpretation of $\mathrm{PbtO} 2$ monitoring in pediatric TBI is a complex issue. Effective and efficacious PbtO2-driven management protocols are yet to be established.

\section{Jugular Venous Oxygen Saturation Monitoring}

Continuous measurement of jugular venous oxygen saturation (SjvO2) is typically evaluated using a fiberoptic catheter positioned in the internal jugular bulb. SjvO2 has been utilized to detect cerebral ischemia after brain injury [67-68]. Perez and colleagues were able to show that two or more measurements of $\mathrm{SjvO} 2$ at $55 \%$ or less were associated with a significantly poor neurological outcome in children with severe brain injuries [69]. Despite the associations of low SjvO2 with adverse neurological sequels, intermittent SjvO2 monitoring has not been shown to alter substantially the management of severely brain-injured individuals amongst clinicians [18]. A high incidence of erroneous readings from SjvO2 monitoring has been reported, which limits the reliability when making crucial management decisions [70].

\section{Cerebral Microdialysis}

Cerebral microdialysis is a tool that can be used to improve the understanding of cerebral energy metabolism [71]. Traditionally used as a research tool, microdialysis is now being brought into the neurointensive care setting with the main goal of identifying early markers of ischemia and cell damage [72]. The system uses a thin, fenestrated, double-lumen catheter inserted into the brain interstitium. It does evaluate markers of cell metabolism (lactate, pyruvate, and glucose), neurotransmitters (glutamate), or tissue damage markers (glycerol) that correlate with a level of outcome [73]. A dialysate is infused into the catheter at a slow rate. There is a semipermeable membrane through which small molecules diffuse across from the interstitium into the dialysate. The specimen is then obtained and sent for analysis at desired intervals.

One of the downsides to this modality is that the data collected is not available for the clinicians in real-time and the neurochemical data that is observed appears to reflect the area where the probe was inserted. Also, the insertion of the catheter alone causes local microtrauma, which can induce an inflammatory reaction. For this reason, sample collection analysis is often postponed by one to two hours [71].

Tolias, et al. reported the first use of microdialysis in children with TBI. This manuscript focused on neurotransmitter levels as well as that of other amino acids [74]. The authors concluded that differences existed regarding excitatory neurotransmitters in the pediatric population relative to prior descriptions in adult literature. Normal limit values for a multitude of small molecules have been created in the adult population but are not determined in children [75].

\section{Electroencephalography (EEG)}

Continuous electroencephalography (cEEG) has been used in the pediatric brain-injured population to identify clinical and subclinical seizures and encephalopathy [76]. The traditional 
method of using cEEG is via scalp electrodes, which often leads to records contaminated by muscle artifact and lack of precise spatial resolution [77]. As a result of this, a novel "mini depth" multi-contact electrode has been developed. Specialized multi-contact electrodes are placed into the cerebral cortex via a burr hole made at the bedside and corticography is recorded. It has been found that through intracortical encephalography (ICE) recordings, many seizures were displayed that were not readily identified on the traditional scalp electrode EEG. Some authors hypothesize that multifocal, poorly synchronized "mini-seizures" may, in fact, contribute to global cortical dysfunction seen after traumatic brain injury. The ultimate goal of using ICE in the future is to develop utilization of an EEG-alarm system, aiding in the prevention of secondary brain injury [77].

Near-infrared Reflective Spectroscopy (NIRS)

Transcranial near-infrared reflective spectroscopy (NIRS) is a non-invasive modality used for monitoring regional intracerebral oxygen saturation. The most commonly utilized commercially available system is the EQUANOX (Nonin Medical, Minneapolis, MN). The device is a lightweight sensor that attaches to the frontal scalp region of the patient. The system can be mounted on a pole and is portable. Specifically, the NIRS looks at brain oxygen delivery and utilization $[65,78]$. NIRS is also used for detecting intracerebral blood volume changes [79]. Kamfl, et al. studied the use of NIRS in adults in the neurointensive care unit and were able to show that NIRS correlated with clinical signs of hypoperfusion and decreased oxygen saturation [80]. The authors were also able to demonstrate a significant difference in regional intracerebral oxygenation between patients with both normal and elevated intracranial pressure, showing that patients with increased ICP, greater than $25 \mathrm{mmHg}$, had lower regional intracerebral oxygen saturation [79-80]. The use of NIRS has been also applied in the setting of assessment for bifrontal regional cortical oxygen saturation in coronary bypass patients. NIRS has demonstrated that this adult patient population had low regional intracerebral oxygen saturation and was linked with cognitive dysfunction, an extended course, and perioperative strokes.

In the setting of the neonatal ICU, NIRS has been used to determine cerebral oxygenation in sick children and has been able to provide important information regarding regional tissue perfusion [78]. However, to date, there have been no studies looking specifically at the use of NIRS with other intracranial pressure/oxygenation monitoring devices. Until such studies are performed, it will be difficult to draw conclusions as to the potential benefit of its use in the pediatric brain-injured population.

\section{Biomarkers}

At the time of a brain insult, support cells and neurons undergo structural damage; this ultimately leads to extravasation of certain proteins into the blood, cerebrospinal fluid, and extracellular matrix. These biomarkers can then be utilized and interpreted in such a way that they may hold predictive value in the degree of parenchymal brain injury [81]. Investigations into various biomarkers have been utilized as an adjunct to predicting neurological outcomes in the pediatric brain-injured population. Ubiquitin c-terminal hydrolase (UCH-L1), alpha IIspectrin breakdown product $145 \mathrm{kDa}$ (SPDP 145), glial fibrillary acidic protein (GFAP), neuronspecific enolase (NSE), S100B, and myelin basic protein (MBP) have specifically been investigated. In the setting of TBI, the biomarkers' concentrations have been analyzed. In a study by Berger and colleagues, higher concentrations of NSE, S100B, and MBP were associated with worse outcomes [82]. Increases in ubiquitin c-terminal hydrolase (UCH-L1) and alpha IIspectrin breakdown product $145 \mathrm{kDa}$ (SPDP 145) have specifically been seen in pediatric subjects with moderate and severe TBI. UCH-L1 and SPDP 145 have also been found to have a stronger correlation with the Glasgow Outcome Scale than NSE, S100B, and MBP [82]. GFAP is 
not found outside the central nervous system and is thus a more specific biomarker. GFAP has also been found to be significantly elevated in pediatric brain-injured patients [83]. Correlation between various biomarkers to different subtypes of brain injuries can be tested to provide a stronger and more specific prognostic value to particular markers.

\section{Conclusions}

Monitoring intracranial pressure is a vital component of the management of the brain-injured pediatric patient. Other types of potentially useful information, aside from ICP, are now being monitored to further aid in the earlier detection of deleterious secondary brain injury. To date, there has been very scant literature correlating traditional ICP monitoring to other modalities that yield different types of diagnostic information. It is warranted to design a study collecting intracranial pressure values derived from an EVD and/or an intraparenchymal pressure monitor and correlate these values to the diagnostic information derived from other non-invasive modalities. There is a need for non-invasive, or at least less invasive ways of monitoring, that can be relied upon. In this regard, normal values of non-invasive monitoring need first to be established in the pediatric population prior to comparing them to that of the injured pediatric brain. In the future, large data analysis and visualization of complex interrelated physiologic signals may yield the safest, least invasive methods of deriving useful information for the optimal care of pediatric TBI patients.

\section{Additional Information}

\section{Disclosures}

Conflicts of interest: In compliance with the ICMJE uniform disclosure form, all authors declare the following: Payment/services info: All authors have declared that no financial support was received from any organization for the submitted work. Financial relationships: All authors have declared that they have no financial relationships at present or within the previous three years with any organizations that might have an interest in the submitted work. Other relationships: All authors have declared that there are no other relationships or activities that could appear to have influenced the submitted work.

\section{References}

1. Ballabh P: Intraventricular hemorrhage in premature infants: mechanism of disease . Pediatr Res. 2010, 67:1-8. 10.1203/PDR.0b013e3181c1b176

2. McKeag H, Christian CW, Rubin D, Daymont C, Pollock AN, Wood J: Subdural hemorrhage in pediatric patients with enlargement of the subarachnoid spaces. J Neurosurg Pediatr. 2013, 11:438-44. 10.3171/2012.12.PEDS12289

3. Rizzi M, De Benedictis A, Marras CE, Palma P, Desiderio F, Rollo M: Ruptured Dissecting Vertebrobasilar Aneurysm in Childhood: What Is the Therapeutic Strategy?. Pediatr Neurosurg. 2012, 48:313-18. 10.1159/000351578

4. Yi JL, Galgano MA, Tovar-Spinoza Z, Deshaies EM: Coil embolization of an intracranial aneurysm in an infant with tuberous sclerosis complex: A case report and literature review. Surg Neurol Int. 2012, 3:129. 10.4103/2152-7806.102944

5. Delaney HM, Rooks VJ, Wolfe SQ, Sawyer TL: Term neonate with intracranial hemorrhage and hereditary hemorrhagic telangiectasia: a case report and review of the literature. J Perinatol. 2012, 32:642-44. 10.1038/jp.2011.146

6. Shin SH, Choi IS, Thomas K, David CA: Combined surgical and endovascular management of a giant fusiform PCA aneurysm in a pediatric patient. A case report. Interv Neuroradiol. 2013, 19:222-27.

7. Soltanolkotabi M, Schoeneman SE, Alden TD, Hurley MC, Ansari SA, DiPatri AJ, Jr., Tomita T, Shaibani A: Onyx embolization of intracranial arteriovenous malformations in pediatric patients. J Neurosurg Pediatr. 2013, 11:431-37. 10.3171/2013.1.PEDS12286

8. Wiegand C, Richards P: Measurement of intracranial pressure in children: a critical review of 
current methods. Dev Med Child Neurol. 2007, 49:935-41. 10.1111/j.1469-8749.2007.00935.x

9. Abe KK, Yamamoto LG, Itoman EM, Nakasone TAF, Kanayama SK: Lumbar puncture needle length determination. Am J Emerg Med. 2005, 23:742-46. 10.1016/j.ajem.2005.03.012

10. Boon JM, Abrahams PH, Meiring JH, Welch T: Lumbar puncture: anatomical review of a clinical skill. Clin Anat. 2004, 17:544-53. 10.1002/ca.10250

11. Lundberg N: Continuous recording and control of ventricular fluid pressure in neurosurgical practice. Acta Psychiatr Scand Suppl. 1960, 36:1-193.

12. Smith M: Monitoring intracranial pressure in traumatic brain injury . Anesth Analg. 2008, 106:240-48. 10.1213/01.ane.0000297296.52006.8e

13. Gambardella G, Zaccone C, Cardia E, Tomasello F: Intracranial pressure monitoring in children: comparison of external ventricular device with the fiberoptic system. Childs Nerv Syst. 1993, 9:470-73. 10.1007/BF00393552

14. Chambers KR, Kane PJ, Choksey MS, Mendelow AD: An evaluation of the camino ventricular bolt system in clinical practice. Neurosurgery. 1993, 33:866-68. 10.1227/00006123199311000-00013

15. Keddie S, Rohman L: Reviewing the reliability, effectiveness and applications of Licox in traumatic brain injury. Nurs Crit Care. 2012, 17:204-12. 10.1111/j.1478-5153.2012.00499.x

16. Narotam PK, Morrison JF, Nathoo N: Brain tissue oxygen monitoring in traumatic brain injury and major trauma: outcome analysis of a brain tissue oxygen-directed therapy. J Neurosurg. 2009, 111:672-82. 10.3171/2009.4.JNS081150

17. Allen BB, Hoffman CE, Traube CS, Weinstein SL, Greenfield JP: Continuous brain tissue oxygenation monitoring in the management of pediatric stroke. Neurocrit Care. 2011, 15:529-36. 10.1007/s12028-011-9531-X

18. Latronico N, Beindorf AE, Rasulo FA, Febbrari P, Stefini R, Cornali C, Candiani A: Limits of intermittent jugular bulb oxygen saturation monitoring in the management of severe head trauma patients. Neurosurgery. 2000, 46:1131-38. 10.1097/00006123-200005000-00021

19. Bell MJ, Kochanek PM, Doughty LA, Carcillo JA, Adelson PD, Clark RS, Wisniewski SR, Whalen MJ, DeKosky ST: Interleukin-6 and interleukin-10 in cerebrospinal fluid after severe traumatic brain injury in children. J Neurotrauma. 1997, 14:451-57. 10.1089/neu.1997.14.451

20. Traumatic Brain Injury in Children. (2013). Accessed: March 19, 2014: http://emedicine.medscape.com/article/909105-overview\#a2.

21. Gradnitzer E, Urlesberger B, Maurer U, Riccabona M, Müller W: Cerebral hemorrhage in term newborn infants--an analysis of 10 years (1989-1999) (Article in German). Wien Med Wochenschr. 2002, 152:9-13. 10.1046/j.1563-258x.2002.01110.x

22. Brouwer AJ, Brouwer MJ, Groenendaal F, Benders MJNL, Whitelaw A, de Vries LS: European perspective on the diagnosis and treatment of posthaemorrhagic ventricular dilatation. Arch Dis Child Fetal Neonatal Ed. 2012, 97:F50-55. 10.1136/adc.2010.207837

23. Wellons JC 3rd, Holubkov R, Browd SR, Riva-Cambrin J, Whitehead W, Kestle J, Kulkarni AV, Hydrocephalus Clinical Research Network: The assessment of bulging fontanel and splitting of sutures in premature infants: an interrater reliability study by the Hydrocephalus Clinical Research Network. J Neurosurg Pediatr. 2013, 11:12-14. 10.3171/2012.10.PEDS12329

24. Kirkpatrick M, Engleman H, Minns RA: Symptoms and signs of progressive hydrocephalus . Arch Dis Child. 1989, 64:124-28. 10.1136/adc.64.1.124

25. Kaiser AM, Whitelaw AG: Intracranial pressure estimation by palpation of the anterior fontanelle. Arch Dis Child. 1987, 62:516-17. 10.1136/adc.62.5.516

26. Chambers IR, Jones PA, Lo TYM, Forsyth RJ, Fulton B, Andrews PJD, Mendelow AD, Minns RA: Critical thresholds of intracranial pressure and cerebral perfusion pressure related to age in paediatric head injury. J Neurol Neurosurg Psychiatry. 2006, 77:234-40. 10.1136/jnnp.2005.072215

27. Czosnyka M, Pickard JD: Monitoring and interpretation of intracranial pressure. J Neurol Neurosurg Psychiatry. 2004, 75:813-21. 10.1136/jnnp.2003.033126

28. Mehta A, Kochanek PM, Tyler-Kabara E, Adelson PD, Wisniewski SR, Berger RP, Sidoni MD, Bell RL, Clark RS, Bell MJ: Relationship of intracranial pressure and cerebral perfusion pressure with outcome in young children after severe traumatic brain injury. Dev Neurosci. 2010, 32:413-19. 10.1159/000316804

29. Le Roux P: Intracranial pressure after the BEST TRIP trial: a call for more monitoring . Curr Opin Crit Care. 2014, 20:141-47. 10.1097/MCC.0000000000000078

30. Tyler KL: Chapter 28: a history of bacterial meningitis . Handb Clin Neurol. 2010, 95:417-33. 


\subsection{6/S0072-9752(08)02128-3}

31. Eide PK, Brean A: Lumbar cerebrospinal fluid pressure waves versus intracranial pressure waves in idiopathic normal pressure hydrocephalus. Br J Neurosurg. 2006, 20:407-14. $10.1080 / 02688690601047312$

32. Lenfeldt N, Koskinen LOD, Bergenheim AT, Malm J, Eklund A: CSF pressure assessed by lumbar puncture agrees with intracranial pressure. Neurology. 2007, 68:155-58.

10.1212/01.wnl.0000250270.54587.71

33. Rosenwasser RH, Kleiner LI, Krzeminski JP, Buchheit WA: Intracranial pressure monitoring in the posterior fossa: a preliminary report. J Neurosurg. 1989, 71:503-5.

10.3171/jns.1989.71.4.0503

34. Langfitt TW, Weinstein JD, Kassell NF, Gagliardi LJ: Transmission of increased intracranial pressure. II. Within the supratentorial space. J Neurosurg. 1964, 21:998-1005. 10.3171/jns.1964.21.11.0998

35. Langfitt TW, Weinstein JD, Kassell NF, Simeone FA: Transmission of increased intracranial pressure. I. Within the craniospinal axis. J Neurosurg. 1964, 21:989-97. 10.3171/jns.1964.21.11.0989

36. Murad A, Ghostine S, Colohan ART: Controlled lumbar drainage in medically refractory increased intracranial pressure. A safe and effective treatment. Acta Neurochir Suppl. Manley G, Hemphill G, Stiver S (ed): Springer-Verlag, Vienna; 2008. 102:89-91. 10.1007/978-3-21185578-2_18

37. Murad A, Ghostine S, Colohan ART: A case for further investigating the use of controlled lumbar cerebrospinal fluid drainage for the control of intracranial pressure. World Neurosurg. 2012, 77:160-65. 10.1016/j.wneu.2011.06.018

38. Tömösvári A, Mencser Z, Futó J, Hortobágyi A, Bodosi M, Barzó P: Preliminary experience with controlled lumbar drainage in medically refractory intracranial hypertension (Article in Hungarian). Orv Hetil. 2005, 146:159-64.

39. Tuettenberg J, Czabanka M, Horn P, Woitzik J, Barth M, Thomé C, Vajkoczy P, Schmiedek P, Muench E: Clinical evaluation of the safety and efficacy of lumbar cerebrospinal fluid drainage for the treatment of refractory increased intracranial pressure. J Neurosurg. 2009, 110:1200-8. 10.3171/2008.10.JNS08293

40. Speck V, Staykov D, Huttner HB, Sauer R, Schwab S, Bardutzky J: Lumbar catheter for monitoring of intracranial pressure in patients with post-hemorrhagic communicating hydrocephalus. Neurocrit Care. 2011, 14:208-15. 10.1007/s12028-010-9459-6

41. Adelson PD, Bratton SL, Carney NA, Chesnut RM, du Coudray HE, Goldstein B, Kochanek PM, Miller HC, Partington MD, Selden NR, Warden CR, Wright DW, American Association for Surgery of Trauma, Child Neurology Society, International Society for Pediatric Neurosurgery, International Trauma Anesthesia and Critical Care Society, Society of Critical Care Medicine, World Federation of Pediatric Intensive and Critical Care Societies: Guidelines for the acute medical management of severe traumatic brain injury in infants, children, and adolescents. Chapter 10. The role of cerebrospinal fluid drainage in the treatment of severe pediatric traumatic brain injury. Pediatr Crit Care Med. 2003, 4:S38-39.

42. Srinivasan VM, O'Neill BR, Jho D, Whiting DM, Oh MY: The history of external ventricular drainage: Historical vignette. J Neurosurg. 2014, 120:228-36. 10.3171/2013.6.JNS121577

43. Raboel PH, Bartek J Jr, Andresen M, Bellander BM, Romner B: Intracranial Pressure Monitoring: Invasive versus Non-Invasive Methods-A Review. Crit Care Res Pract. 2012, 2012:950393. 10.1155/2012/950393

44. Ngo QN, Ranger A, Singh RN, Kornecki A, Seabrook JA, Fraser DD: External ventricular drains in pediatric patients. Pediatr Crit Care Med. 2009, 10:346-51. 10.1097/PCC.0b013e3181a320cd

45. Roitberg BZ, Khan N, Alp MS, Hersonskey T, Charbel FT, Ausman JI: Bedside external ventricular drain placement for the treatment of acute hydrocephalus. Br J Neurosurg. 2001, 15:324-27. 10.1080/02688690120072478

46. Mayans DR, Meads DB, Reynolds PS: Transcranial Doppler identifies a malfunctioning extraventricular drain. J Neuroimaging. 2014, 24:518-19. 10.1111/jon.12016

47. Melo JRT, Di Rocco F, Blanot S, Cuttaree H, Sainte-Rose C, Oliveira-Filho J, Zerah M, Meyer PG: Transcranial Doppler can predict intracranial hypertension in children with severe traumatic brain injuries. Childs Nerv Syst. 2011, 27:979-84. 10.1007/s00381-010-1367-8

48. Figaji AA, Zwane E, Fieggen AG, Siesjo P, Peter JC: Transcranial Doppler pulsatility index is not a reliable indicator of intracranial pressure in children with severe traumatic brain injury. 
Surg Neurol. 2009, 72:389-94. 10.1016/j.surneu.2009.02.012

49. Bouma GJ, Muizelaar JP, Bandoh K, Marmarou A: Blood pressure and intracranial pressurevolume dynamics in severe head injury: relationship with cerebral blood flow. J Neurosurg. 1992, 77:15-19. 10.3171/jns.1992.77.1.0015

50. Sahuquillo J, Munar F, Baguena M, Poca MA, Pedraza S, Rodríguez-Baeza A: Evaluation of cerebrovascular $\mathrm{CO} 2$-reactivity and autoregulation in patients with post-traumatic diffuse brain swelling (diffuse injury III). Acta Neurochir Suppl. 1998, 71:233-36. 10.1007/978-37091-6475-4_67

51. Udomphorn Y, Armstead WM, Vavilala MS: Cerebral blood flow and autoregulation after pediatric traumatic brain injury. Pediatr Neurol. 2008, 38:225-34.

10.1016/j.pediatrneurol.2007.09.012

52. Vavilala MS, Lee LA, Boddu K, Visco E, Newell DW, Zimmerman JJ, Lam AM: Cerebral autoregulation in pediatric traumatic brain injury. Pediatr Crit Care Med. 2004, 5:257-63. 10.1097/01.PCC.0000123545.69133.C3

53. Panerai RB, Kerins V, Fan L, Yeoman PM, Hope T, Evans DH: Association between dynamic cerebral autoregulation and mortality in severe head injury. Br J Neurosurg. 2004, 18:471-79. 10.1080/02688690400012343

54. Steiner LA, Czosnyka M, Piechnik SK, Smielewski P, Chatfield D, Menon DK, Pickard JD: Continuous monitoring of cerebrovascular pressure reactivity allows determination of optimal cerebral perfusion pressure in patients with traumatic brain injury. Crit Care Med. 2002, 30:733-38. 10.1097/00003246-200204000-00002

55. Vavilala MS, Muangman S, Tontisirin N, Fisk D, Roscigno C, Mitchell P, Kirkness C, Zimmerman JJ, Chesnut R, Lam AM: Impaired cerebral autoregulation and 6-month outcome in children with severe traumatic brain injury: preliminary findings. Dev Neurosci. 2006, 28:348-53. 10.1159/000094161

56. Bekar A, Doğan S, Abaş F, Caner B, Korfali G, Kocaeli H, Yilmazlar S, Korfali E: Risk factors and complications of intracranial pressure monitoring with a fiberoptic device. J Clin Neurosci. 2009, 16:236-40. 10.1016/j.jocn.2008.02.008

57. Al-Tamimi YZ, Helmy A, Bavetta S, Price SJ: Assessment of zero drift in the Codman intracranial pressure monitor: a study from 2 neurointensive care units. Neurosurgery. 2009, 64:94-98. 10.1227/01.NEU.0000328392.98602.5A

58. Rumana CS, Gopinath SP, Uzura M, Valadka AB, Robertson CS: Brain temperature exceeds systemic temperature in head-injured patients. Crit Care Med. 1998, 26:562-67. 10.1097/00003246-199803000-00032

59. Friess SH, Kilbaugh TJ, Huh JW: Advanced neuromonitoring and imaging in pediatric traumatic brain injury. Crit Care Res Pract. 2012, 2012:361310. 10.1155/2012/361310

60. Dings J, Meixensberger J, Jäger A, Roosen K: Clinical experience with 118 brain tissue oxygen partial pressure catheter probes. Neurosurgery. 1998, 43:1082-95. 10.1097/00006123199811000-00045

61. Meixensberger J, Jaeger M, Väth A, Dings J, Kunze E, Roosen K: Brain tissue oxygen guided treatment supplementing ICP/CPP therapy after traumatic brain injury. J Neurol Neurosurg Psychiatr. 2003, 74:760-64. 10.1136/jnnp.74.6.760

62. Narotam PK, Burjonrappa SC, Raynor SC, Rao M, Taylon C: Cerebral oxygenation in major pediatric trauma: its relevance to trauma severity and outcome. J Pediatr Surg. 2006, 41:50513. 10.1016/j.jpedsurg.2005.11.069

63. Figaji AA, Zwane E, Thompson C, Fieggen AG, Argent AC, Le Roux PD, Peter JC: Brain tissue oxygen tension monitoring in pediatric severe traumatic brain injury. Part 1: Relationship with outcome. Childs Nerv Syst. 2009, 25:1325-33. 10.1007/s00381-009-0822-X

64. Figaji AA, Zwane E, Thompson C, Fieggen AG, Argent AC, Le Roux PD, Peter JC: Brain tissue oxygen tension monitoring in pediatric severe traumatic brain injury. Part 2: Relationship with clinical, physiological, and treatment factors. Childs Nerv Syst. 2009, 25:1335-43. 10.1007/s00381-009-0821-y

65. Kasman N, Brady K: Cerebral oximetry for pediatric anesthesia: why do intelligent clinicians disagree?. Paediatr Anaesth. 2011, 21:473-78. 10.1111/j.1460-9592.2011.03549.x

66. Stippler M, Ortiz V, Adelson PD, Chang YF, Tyler-Kabara EC, Wisniewski SR, Fink EL, Kochanek PM, Brown SD, Bell MJ: Brain tissue oxygen monitoring after severe traumatic brain injury in children: relationship to outcome and association with other clinical parameters. J Neurosurg Pediatr. 2012, 10:383-91. 10.3171/2012.8.PEDS12165 
67. Sheinberg M, Kanter MJ, Robertson CS, Contant CF, Narayan RK, Grossman RG: Continuous monitoring of jugular venous oxygen saturation in head-injured patients. J Neurosurg. 1992, 76:212-17. 10.3171/jns.1992.76.2.0212

68. Gopinath SP, Robertson CS, Contant CF, Hayes C, Feldman Z, Narayan RK, Grossman RG: Jugular venous desaturation and outcome after head injury . J Neurol Neurosurg Psychiatr. 1994, 57:717-23. 10.1136/jnnp.57.6.717

69. Pérez A, Minces PG, Schnitzler EJ, Agosta GE, Medina SAP, Ciraolo CA: Jugular venous oxygen saturation or arteriovenous difference of lactate content and outcome in children with severe traumatic brain injury. Pediatr Crit Care Med. 2003, 4:33-38. 10.1097/00130478-20030100000006

70. Murr R, Schürer L, Polasek J: Continuous fiberoptic monitoring of oxygen saturation in cerebral veins in severe craniocerebral trauma--experiences and results (Article in German). Anasthesiol Intensivmed Notfallmed Schmerzther. 1996, 31:29-36.

71. de Lima Oliveira M, Kairalla AC, Fonoff ET, Martinez RC, Teixeira MJ, Bor-Seng-Shu E: Cerebral microdialysis in traumatic brain injury and subarachnoid hemorrhage: state of the art. Neurocrit Care. 2014, 21:152-62. 10.1007/s12028-013-9884-4

72. Charalambides C, Sgouros S, Sakas D: Intracerebral microdialysis in children . Childs Nerv Syst. 2010, 26:215-20. 10.1007/s00381-009-1031-3

73. Sanchez JJ, Bidot CJ, O'Phelan K, Gajavelli S, Yokobori S, Olvey S, Jagid J, Garcia JA, Nemeth Z, Bullock R: Neuromonitoring with microdialysis in severe traumatic brain injury patients . Acta Neurochir Suppl. 2013, 118:223-27. 10.1007/978-3-7091-1434-6_42

74. Tolias CM, Richards DA, Bowery NG, Sgouros S: Extracellular glutamate in the brains of children with severe head injuries: a pilot microdialysis study. Childs Nerv Syst. 2002, 18:36874.

75. Hillered L, Vespa PM, Hovda DA: Translational neurochemical research in acute human brain injury: the current status and potential future for cerebral microdialysis. J Neurotrauma. 2005, 22:3-41. 10.1089/neu.2005.22.3

76. O'Neill BR, Handler MH, Tong S, Chapman KE: Incidence of seizures on continuous EEG monitoring following traumatic brain injury in children. J Neurosurg Pediatr. 2015, 16:167-76. 10.3171/2014.12.PEDS14263

77. Waziri A, Claassen J, Stuart RM, Arif H, Schmidt JM, Mayer SA, Badjatia N, Kull LL, Connolly ES, Emerson RG, Hirsch LJ: Intracortical electroencephalography in acute brain injury . Ann Neurol. 2009, 66:366-77. 10.1002/ana.21721

78. Brazy JE, Lewis DV, Mitnick MH, Jöbsis vander Vliet FF: Noninvasive monitoring of cerebral oxygenation in preterm infants: preliminary observations. Pediatrics. 1985, 75:217-25.

79. Rosenberg JB, Shiloh AL, Savel RH, Eisen LA: Non-invasive methods of estimating intracranial pressure. Neurocrit Care. 2011, 15:599-608. 10.1007/s12028-011-9545-4

80. Kampfl A, Pfausler B, Haring HP, Denchev D, Donnemiller E, Schmutzhard E: Impaired microcirculation and tissue oxygenation in human cerebral malaria: a single photon emission computed tomography and near-infrared spectroscopy study. Am J Trop Med Hyg. 1997, 56:585-87.

81. Menascu S, Brezner A, Tshechmer SM, Rumeny PG: Serum biochemical markers for brain damage in children with emphasis on mild head injury. Pediatr Neurosurg. 2010, 46:82-88. 10.1159/000319004

82. Berger RP, Beers SR, Richichi R, Wiesman D, Adelson PD: Serum biomarker concentrations and outcome after pediatric traumatic brain injury. J Neurotrauma. 2007, 24:1793-1801. 10.1089/neu.2007.0316

83. Fraser DD, Close TE, Rose KL, Ward R, Mehl M, Farrell C, Lacroix J, Creery D, Kesselman M, Stanimirovic D, Hutchison JS, Canadian Critical Care Translational Biology Group: Severe traumatic brain injury in children elevates glial fibrillary acidic protein in cerebrospinal fluid and serum. Pediatr Crit Care Med. 2011, 12:319-24. 10.1097/PCC.0b013e3181e8b32d 